\title{
Impact of academic nurse-managed centers on communities served
}

Joanne M. Pohl, PhD, APRN, BC, FAAN (Associate Dean, Office for Community Partnerships and Professor, Adult Nurse Practitioner) ${ }^{1}$, Violet H. Barkauskas, PhD, RN, FAAN (Associate Professor and Community Health Nursing Specialist) ${ }^{1}$, Ramona Benkert, PhD, APRN, BC (Assistant Professor and Adult Nurse Practitioner) ${ }^{2}$, Lynn Breer, PhD (Deputy Director) ${ }^{3}$, \& Andrea Bostrom, PhD, APRN, BC (Associate Dean for Academic Programs and Associate Professor) ${ }^{4}$

1 School of Nursing, University of Michigan, Ann Arbor, Michigan

2 College of Nursing, Wayne State University, Detroit, Michigan

3 Center for Collaborative Research in Health Outcomes and Policy, Michigan Public Health Institute, Okemos, Michigan

4 Kirkhof College of Nursing, Grand Valley State University, Cook-DeVos Center for Health Sciences, Grand Rapids, Michigan

\section{Keywords}

Community evaluation; nurse-managed

centers; access to care; nurse practitioners.

\section{Correspondence}

Joanne M. Pohl, PhD, APRN, BC, FAAN, School of Nursing, University of Michigan, 400 North Ingalls Street, Ann Arbor, MI 48109-0482.

Tel: 734-936-3631; Fax: 734-936-3644;

E-mail: jpohl@umich.edu

Received: March 2006; accepted: August 2006

doi:10.1111/j.1745-7599.2007.00224.x

\begin{abstract}
Purpose: This paper presents findings from six community focus groups that addressed the impact of academic nurse-managed centers (ANMCs) on the overall community being served as well as the quality of care provided in the centers.

Data sources: Experts in focus group methodology from a public health institute conducted the six focus groups at ANMCs from four universities in the Midwest. Discussions were guided by nine questions presented to each group. All groups were tape-recorded and transcribed. A total of 37 participants were recruited from the ANMCs and included patients and families, advisory board members, and local community organizations.

Conclusions: Four themes were identified across the six focus groups: valuing patient-centered care, which included two subthemes-continuous specific provider and specific aspects of care; quality of care; increasing access to care/addressing the safety net; and evidence of outreach.

Implications for practice: Findings from these focus groups verify that community members do "get it" in terms of the unique aspects of ANMCs. Participants were able to articulate the differences between nurse-managed care and other types of ambulatory primary care. The unique strengths of nurse practitioners were repeatedly articulated as well as the centers' outreach into the community.
\end{abstract}

\section{Introduction}

Academic nurse-managed centers (ANMCs) have been rooted historically in the communities they serve (e.g., Kerekes, Jenkins, \& Torissi, 1996; Lundeen, 1999; Oros, Johantgen, Antol, Heller, \& Ravella, 2001), and many use the word "community" in their names. In many ways, nurse-managed centers date back to community health visionaries such as Lillian Wald at the turn of the 20th century (Glass, 1989). While there is increasing evaluation of ANMCs in terms of outcomes of care, cost of care, and patient satisfaction, limited documentation of the overall impact of ANMCs on the communities they serve exists despite the philosophical emphasis on community.

Few studies have sought to broadly evaluate community impact of nurse-managed centers (Edwards, Kaplan, Barnett, \& Lee-Logan, 1998). The purpose of this article is to present the findings from six community focus groups that were conducted as part of an evaluation of a fouruniversity consortium, the Michigan Academic Consortium, which addressed the impact of ANMCs on the overall community. 
ANMCs are innovative models of health care that offer direct access to full primary care services provided by nurse practitioners (NPs) and midwives along with other healthcare personnel. Direct access to nursing services is key in these ANMCs because the providers of care are advanced practice nurses. ANMCs also frequently provide care to safety net populations such as those with limited or no insurance, those on Medicaid, and other more vulnerable populations (Fren, Lundeen, Martin, Riesch, \& Wilson, 1996; Glick, 1999; Pohl, Vonderheid, Barkauskas, \& Nagelkerk, 2004). These ANMCs are unique educational laboratories for NP students, as well as other nursing and nonnursing students at all levels of educational preparation, to further understand the community perspective of the clients served (Tanner, Pohl, Ward, \& Dontje, 2003). The community emphasis has been consistent and strong for many ANMCs; yet, few or no studies exist that actually describe the community's response to ANMCs.

\section{Review of the literature}

Attention in the literature to the community component of ANMCs has been evident for many years. Lundeen's model of Community Nursing Centers (1999) suggests that community needs drive services, and services offered in nursing centers support the health and well-being of all community members, not just those seeking services. Fawcett et al. (2001) identified reasons why community evaluation is necessary.

Providing ongoing feedback can improve community work by encouraging continuous adjustments of programs, policies, and other interventions; by involving community members, people who haven't had a voice may gain the opportunity to better understand and improve local efforts; ... evaluation can help hold groups accountable to the community and to the grant makers who provide funding. (p. 2)

Actual reports of evaluation of ANMCs from a community perspective are very limited in the literature. One study sought to broadly evaluate community impact (Edwards et al., 1998). Edwards et al. assessed morbidity and mortality statistics in a targeted significantly underserved rural county served by an ANMC. Cardiovascular deaths fell dramatically in the ANMC following the service delivery. More commonly, studies have focused on the impact of targeted community screening (MacNee, Hemphill, \& Letran, 1996; Tyree, Henly, Schauer \& Lindsey, 1998) or wellness clinics (Taylor, Resnick, D'Antonio, \& Carroll, 1997) run by NPs or community health faculty with their students as adjuncts to the ANMC primary care delivery.
Scott and Moneyham (1995a) provided the only report of a community-based, randomly selected qualitative evaluation of a nursing center. Using focus group methodology, Scott and Moneyham conducted four distinct focus groups of residents of a senior living center. The groups were composed of community residents who used the center regularly, community residents who had never used the center, community residents who served on the advisory board, and residents who had used the center in the past but who had not done so in the previous 6 months. Three major themes identified were feeling valued and respected, opening doors to self-care, and decreasing self-care costs. The findings offered an understanding of the value of nursing centers as well as a community perspective from a diverse group of community residents. In another report using the same data, Scott and Moneyham (1995b) reported that focus group participants described being caught between limitations in the "old medical paradigm" when they tried to use the nursing center, while fully understanding the gaps in the existing healthcare system. Participants valued the services of the center but ran into system issues (i.e., lack of acceptance of the NP providers by physicians in the larger health system) when they used the center for primary care.

Authors from another study in New Zealand (Clendon 8 Krothe, 2004) reported on focus group findings of stakeholders $(N=13)$ that were part of an evaluation study of a nurse-managed primary care clinic. The authors used what they referred to as Fourth Generation Evaluation (Guba \& Lincoln, 1989), where the "stakeholders are creators of knowledge" (p. 17). Clendon and Krothe found four categories in their focus groups: factors that contribute to success, contrasting past experience of health care with that of nurse-managed care, the effectiveness of nurse-managed care, and suggestions for change in current practice.

The literature limitations likely reflect the clear challenges in evaluating community impact of services. Individual stories of success and change are compelling and are often available in a short timeframe. They also take less effort to capture. Evaluating the impact of care on a community is very complex, involves multiple evaluation foci, and often takes a long time to realize the impact or change (Fawcett et al., 2001). Evaluation at the community level is labor intensive and can stretch small already overburdened organizations such as ANMCs beyond their resources. Fawcett et al. reported that it is often difficult in one evaluation process to do more than understand what is going on.

Principles of community evaluation include the following (Fawcett et al., 2001):

- Community initiatives are complex and ever changing and must be analyzed on multiple levels 
- Community evaluation must understand and reflect the issues and the context in which it is happening

- Community evaluation information should be linked to questions of importance to key stakeholders

- Community evaluation should start early and be ongoing/continuous

- Community evaluation results, if positive, should be used to help sustain and promote widespread adoption of the initiative.

\section{Methods}

\section{Procedure}

This article presents the results from six focus groups representing six ANMCs and the four universities who are partners in the Michigan Academic Consortium. A fifth partner in the consortium, The Michigan Public Health Institute (MPHI), served a fiduciary role for the project and, through its Center for Collaborative Research in Health Outcomes and Policies, facilitated the evaluation process. Central to the mission of the consortium was providing community-responsive primary care in ANMCs in collaboration with the communities being served. The term community was defined in this project as the population being served by the center. In one case, the population focus was veterans, while most of the other centers addressed communities in a more specific geographical area. The six ANMCs that participated in the focus groups are described in Table 1. Quantitative data on patient satisfaction in these centers have been reported elsewhere (Benkert, Barkauskas, Pohl, Tanner, \& Nagelkerk, 2002).

Community focus groups were conducted in the final year of the funded project at seven of the centers in the consortium as part of the evaluation process. The content from one of the seven centers was not included in the final analysis as an administrator of the facility walked in during the focus group and stayed, although all center and facility staff had been asked not to participate. It was felt that this person's presence had too great an impact on the conversation for inclusion in the analysis. The remaining six focus groups had a total of 37 participants. Participants were recruited by clinic staff and included stakeholders from each nursing center.

Investigational Review Board approval was obtained for the focus groups. Focus groups were led by experts in qualitative research methods from MPHI, and a faculty member, not from the university where the focus group was being held, also participated. Faculty and staff from the university and center being interviewed were excluded from participation to promote maximum confidentiality. Participants were informed of the purpose of the focus group and signed consent to participate. The focus group discussion was guided by nine questions regarding the impact of the ANMC on the surrounding/relevant community (Table 2).

\section{Sample}

The focus groups ranged in size from three to nine participants and comprised patients who used the centers for care, advisory board members, families of patients, and local community organizations. Of the 37 participants, 23 were females and 14 were males, and all were over 18 years of age. No further demographics were obtained. The data presented are an aggregate summary from all six focus groups.

All focus groups were tape-recorded and transcribed. Experts in focus group methodology from MPHI and the consortium reviewed the transcripts and coded them for themes. Four main themes were identified with subthemes identified in the first theme. They are listed in Table 3

Table 1 Consortium nurse-managed centers: Year established, setting, and clients

\begin{tabular}{|c|c|c|}
\hline University/center, year established & Setting & Clients/insurance plans/No. of visits (2001 data) \\
\hline \multicolumn{3}{|l|}{ University 1} \\
\hline Center A, 1999 & Campus housing & Faculty, staff, and students/commercial/6943 \\
\hline Center B, 1999 & Urban, public housing unit & Underserved, low income/public, uninsured/1677 \\
\hline \multicolumn{3}{|l|}{ University 2} \\
\hline Center C & Urban, medical center outpatient facility & Veterans, low income/public/4764 \\
\hline Center $D^{a}, 1997$ & Urban, residential & Low to middle income/commercial, public, uninsured/2842 \\
\hline Center $E^{b}, 1991$ & Urban, campus-based family housing unit & Students, faculty, and staff/commercial, public, uninsured/4200 \\
\hline \multicolumn{3}{|l|}{ University 4} \\
\hline Center F, 1979 & Urban, medical center outpatient facility & Low income/commercial, public, uninsured/4641 \\
\hline
\end{tabular}

${ }^{a}$ An affiliated outreach clinic serves residence in a public housing development.

${ }^{\mathrm{b}}$ An affiliated outreach clinic is a shelter that serves women and children that are victims of domestic violence. 
Table 2 List of focus group questions

1. Could you begin by talking about how you use the center's services or what you know about the services offered at the center?

2. What does the nursing center bring to the community?

3. What is different in the community as a result of this center?

4. How could the center be more responsive to the community's needs and issues?

5. How well is the community informed of the center's services?

6. What would help to inform them better?

7. Do people in the community have access to primary health care?

8. Do you think there are enough opportunities for community members to be involved in planning for health services? Why or why not?

9. How might the nurse-managed center increase participation from community members such as yourselves?

\section{Results}

The results are presented based on the four themes using examples representing each theme.

\section{Valuing patient-centered care}

The first theme, valuing patient-centered care included two subthemes: (a) continuous specific provider and (b) specific aspects of care. Comments related to patient-centered care were a major discussion item in every focus group.

\section{Continuous specific provider}

Participants commented on the importance of a continuous relationship with a particular NP. Comments such as the following reflected the overall statements: "we feel very comfortable with her care", or "... it gives you more continuity of care also. Because you have your specific provider that sees you on a regular basis so they're quite familiar with your healthcare needs."

\section{Specific aspects of care}

In addition to valuing a continuous provider at the nurse-managed centers, three specific aspects of care were

Table 3 Themes and subthemes from focus groups

1. Valued patient-centered care
(a) Continuous specific NP
(b) Specific aspects of care
(i) Case management and coordination of care (working with
the health system)
(ii) Caring, listening, taking time
(iii) Responsiveness
2. Quality of care
3. Increasing access to care/addressing the safety net
4. Evidence of outreach

identified as important to the participants in these focus groups. These included case management including coordination of care and gateway to referrals; caring, listening, and taking time; and responsiveness.

Case management and coordination of care through complex systems were cited as a value of the nurse-managed centers. Respondents talked about how the ANMCs gave them access to specialty care. One woman stated that "You can come here and this is how you can get to see a specialist, through seeing a nurse care provider." At another site's focus group, a participant stated that the nurse-managed center was as follows:

... a gateway for complex and advanced care. It allows the beginning steps toward getting more complicated care if it is required, without oneself trying to figure out how to get that in the city. So specialists are available through this system and they can be made accessible.

One participant, a university student at the time as well as a patient, talked about how the center coordinated his care after surgery so that he could continue school and not lose a semester.

... and I didn't want to take a whole semester off just because of this wound. Well, we called up the center; we really weren't sure what to do, especially with my insurance ... My mom talked to (the nurse practitioner) and it was like, no problem .... And every morning I'd just go there and it was like you said, it'd be so much better of a time saver, especially you know, I'm on campus.

Another respondent said, "Like I see about four or five different other doctors, I mean doctors. And then they just send her a report ... she's primary, she coordinates everything."

Caring, listening, and taking time was another subtheme that appeared in three of the focus groups. "They're very thorough and they listen, more so than the doctors. It's like they have more of a listening ear." Another participant put it this way, "They take a lot of time with you ... it's like you got a problem today and you just walk in tomorrow and they'll take you." The following quote from a member of a community mental health organization who was not a patient in the ANMC spoke to the center's relationship with the mental health community.

Mental health consumers feel like they have the support here ... having people respect them, understand them, and not be judgmental is absolutely wonderful. It speaks to the understanding and sensitivity and the caring manner in which the clinic lends itself.

The following comment seems to summarize the subtheme of caring, listening, and taking time: "You know each one takes time, with every individual, you know. 
Ever since I've been coming here I've found that. And also, they're very understanding. You go to a lot of places; you don't get that kind of care."

Responsiveness, another subtheme identified in specific aspects of care was addressed in several of the focus groups. A quote from one person representing a center that deals with a high need population summarizes the comment around patient-centered care/responsiveness: “... like I said, but if I need something, they are right there to help me." In another focus group, a respondent indicated satisfaction with not having to wait long times in the office before being seen and the NPs were responsive to that issue: "You know, when you go to a doctor's office you wait 3, 4 hours; here you might wait 20, 30 minutes, but very rare. And they do provide a great health environment for people." Another respondent noted that after an urgent need for a same day visit "They took time out of their busy day and would see me and take care of me. That was wonderful." One respondent put it this way when talking about the on-call system: "... and they will follow-up and call you. That is like getting the doctor to come out in the middle of the night."

\section{Quality of care}

Quality of care was another major theme in all of the focus groups. The term quality was actually used by many of the participants. Because all of these centers serve underserved populations, some of the respondents' comments on quality compared their care experiences at the center with that of previous settings and providers. One aspect of quality, thoroughness, was described including thoroughness of care and also thoroughness of documentation of the care. For example, one participant stated that

... she makes notes of everything that's wrong with you ... if you have to go to court on something, or whatever, and they wanna [sic] know your medical history, she has it written down .... See, that's what's important, this is what makes this really nice for us.

An older adult patient in one of the focus groups stated that "And then the type of care you get here. I mean it's caring, follow-up. We've never had care like this in our 75 years." Another woman in the same group stated that "... the nurses here have been able to figure out what was ailing me through the years that I never figured out or other doctors could not figure out." Another comment that reflects thoroughness and satisfaction with the quality of care was from a male patient: "But here you can come and they can advise you, they can treat you, and if necessary send you to somebody else. But, you just cannot get that kind of care anywhere else in the city." Another patient put it this way: "I go to the nurse managed center ... there's more time with my provider, and you know, so very high quality healthcare ...."

\section{Increasing access to care/addressing the safety net}

This theme received the most comments across all of the focus groups. Clearly, the centers are perceived as serving a safety net function in their communities. Comments ranged from access to primary care, convenience of location, access to specialty care, access to care that kept individuals out of the emergency department, access to same day or timely appointments, telephone access, access to pharmaceuticals, and access to quality care. There were also comments on wanting more access in terms of clinic hours. Representative comments included the following:

I think that it's a place for the patients, the community, for the people in the community to come to. It's readily available especially in the inner city. And I find that they are more (sic), and they do more teaching in the health care.

In a discussion on the uninsured in one focus group, an uninsured participant talked about how the NPs assisted with insurance forms and pharmaceuticals, increasing access to both. Several respondents addressed how the access to primary care in the nurse-managed centers kept them out of the emergency room.

Now we have medical service; before we did not. If I was sick before, I would just stay in the building. And it was either stay up there and hope to get well, or if you got that sick, call an ambulance.

Other comments around access to care focused on the geographical location and comfort with the manageable size of the centers and their community-based location, making them accessible to care. One patient summed it up this way:

It's good because it is a neighborhood clinic and the neighborhood side of it means that it is accessible to people, it is within walking distance of the bus line, so we see it as a neighborhood clinic. Before this clinic was here there was nothing ... the people who I work with their main clinic was urgent care. ... or it was fighting the battle of going down to .... hospital, which is as everybody knows a big, gigantic maze of corridors.

Another respondent in the same focus group commented on her satisfaction with access saying, "Personally, just instant access. You come in, always room for someone ... and luckily we live in the neighborhood." One woman's comments seem to reflect what was said across the focus groups: "If the clinic was not here it would be a real disaster, you can believe that."

Comments that focused on wanting more access in terms of clinic schedule included "I think it is wonderful they stay open late .... I would love to see Saturday hours 
or you know, some extended hours" (there was general agreement among the other participants in the group). Comfort with the care environment was also discussed in one focus group as a component of access. "Well I guess it's not only accessing, it's also the comfort level .... When you go there you know for sure that they will be understood." Another participant added on, "It's just that cultural sensitivity."

\section{Evidence of outreach}

Outreach activities by some of the centers were highly valued and respected by focus group participants. Two of the centers had outreach services in public housing, a teen center, and a domestic violence shelter, and a majority of the comments came from the focus groups from those centers. However, two other groups talked about outreach when they addressed marketing issues and how the community knows about the centers. One of the centers had a lay outreach health worker as part of the staff. Some of the centers also offered home visits and one of the centers had programs in the community for seniors. When talking about unique features of the nurse-managed center, a participant stated that

I think the other thing that is exciting about the clinic is the level of outreach. I mean, they have gone door to door. What other health care takes the time to knock on doors and say "hey, the service is available, we welcome you." I think that has been a real positive asset so that it is open, it is available, affordable, and caring.

In the focus group at the center employing a part-time community outreach worker, very positive comments were made about the role and commitment of the center to outreach. "That person is an outreach person who is a part of the community, knows that community well, and has access into people's homes and neighborhoods in such a way that she is representative of them as well as us." Another woman in the same focus group then went on to say: "Not only did she provide outreach to potential clients and patients, but she enabled connections, partnerships by introducing the administration people to upper city or county or community mental health individuals so that there have been increasing partnerships built ...." Another participant put it this way in terms of the importance of outreach: "Not just expecting people to come in, but really working to reach out to some of the areas where people might not otherwise choose to come."

\section{Additional findings}

The focus group participants made comments on how the centers could improve their services or to increase awareness of the clinic in the community. In almost every focus group, the participants indicated that awareness could be increased through expanded marketing efforts. Ironically, however, the participants did not want the centers to become too large and lose their community orientation and high quality of care. Other recommendations included advice about center services such as longer hours, Saturday hours, a larger space, offering more home visits, and increased staffing. Respondents were also sensitive to centers' funding challenges.

Participants supported more community input through advisory boards and additional focus groups. They were enthusiastic about the opportunity to participate in the focus group and to provide their opinions about the centers and their NPs.

\section{Discussion}

Findings need to be viewed and applied with caution. The focus group respondents were selected by center staffs and were likely to be responsive clients or friends of the centers. Also, the study was conducted in a small cluster of centers in a specific geographic area. Despite these limitations, findings provide some interesting insights into what community members understand and appreciate about ANMC care.

First, the findings support the Institute of Medicine's (IOM, 2001) recommendation that quality health care involves patient-centered care, which is reflected by qualities such as compassion, responsiveness, being listened to, and participating in their care decision. Similar to the previous reports on nurse-managed centers (Clendon $\delta$ Krothe, 2004; Scott \& Moneyham, 1995a, 1995b), findings in the current study verify that respondents in these focus groups did "get it" about the unique aspects of ANMCs - the notions of health (not just medical) care, comprehensive care and follow-through with problems and concerns, prevention, teaching, and listening. Respondents were able to articulate the differences between nursemanaged care and other types of ambulatory primary care and the unique strengths of NP approaches. Findings from these studies are beginning to support common themes across nurse-managed centers.

Interestingly, respondents in these focus groups actually found increased access to specialty care in the larger healthcare system-that is, they felt they had entree into the medical system through the nurse-managed centers in contrast to Scott and Moneyham's (1995b) findings where community residents reported being caught between the "old medical paradigm" and nurse-managed center. These findings may be the result of an improved "climate" for NPs given that this study was conducted several years after Scott and Moneyham's research. Another explanation may be the differences in location of the centers. Scott 
and Moneyham's participants were from a senior high rise with less direct access to the local health system, whereas several of the centers in this study were associated with an academic medical center.

Respondents were clear and articulate about the importance of the centers to the communities served. They recognized the notion and importance of "safety net" and accessibility factors. In addition, respondents acknowledged and deeply valued the notion of the centers' outreach into the community. Despite differences in center sponsorship and community composition, the responses across centers were surprisingly similar in terms of satisfaction with NP care and the advantages of ANMC primary care. Additionally, community members across focus groups desired more participation on advisory boards and other ways to assure the ongoing success of the centers. They were quite aware of the vulnerability of the centers as they served diverse populations.

The literature review documented the paucity of and difficulty associated with obtaining community impact evaluation data. The focus group methodology for obtaining impact data proved feasible and useful in the current project. The study's generalizability is limited by its geographic locality, by the possibly biased selection of ANMC friends, and by limited participant demographic data. Several recommendations are presented for centers considering this evaluation approach. First, the use of outside staff to conduct the focus groups was important to avoid possible bias imposed by center staff leading the groups. Second, more standardization of focus group participants would produce more comparable results over time. That is, some combination of patients, community leaders, and community partners is desirable. Third, feedback to center staff proved a powerful validation experience.

\section{Conclusions}

Despite the noted limitations, the respondents substantiated and clearly understood the value of primary care as defined by the IOM (2001). The findings reveal that in these selected nursing centers, participants are receiving patient-centered, integrated, and continuous care in the context of family and community. They are reaching out into the community they serve in unique ways.

\section{Acknowledgment}

This project was funded by the W. K. Kellogg Foundation.

\section{References}

Benkert, R., Barkauskas, V., Pohl, J. M., Tanner, C., \& Nagelkerk, J. (2002). Patient satisfaction outcomes in nurse managed centers. Outcomes Management for Nursing Practice, 6(4), 174-181.

Clendon, J., \& Krothe, J. (2004). The nurse-managed clinic: An evaluative study. Nursing Praxis in New Zealand, 20(2), 15-23.

Edwards, J. B., Kaplan, A., Barnet, J. T., \& Lee-Logan, C. (1998). Nurse-managed primary care in a rural community: Outcomes of five years of practice. Nursing and Health Care Perspectives, 19(1), 20-25.

Fawcett, S. B., Paine-Andrews, A., Francisco, V. T., Schultz, J. Richter, K. P., Berkley-Patton, J., et al. (2001). Evaluating community initiatives for health and development. In I. Rootman \& D. McQueen et al. (Eds.), Evaluating health promotion approaches. Copenhagen, Denmark: World Health Organization.

Fren, M., Lundeen, S. P., Martin, K. S., Riesch, S. K., \& Wilson, S. A. (1996). Symposium on nursing centers: Past, present and future. Journal of Nursing Education, 35(2), 54-62.

Glass, L. K. (1989). The historic origins of nursing centers. In Nursing centers: Meeting the demand for quality health care (pp. 21-34). New York: National League for Nursing.

Glick, D. F. (1999). Advanced practice community health nursing in community nursing centers: A holistic approach to the community as client. Holistic Nursing Practice, 13(4), 19-27.

Guba, E., \& Lincoln, Y. (1989). Fourth generation evaluation. Newbury Park, CA: Sage Publications.

Institute of Medicine. (2001). Crossing the quality chasm: A new health system for the 21st century. Washington, DC: National Academy Press.

Kerekes, J. J., Jenkins, M., \& Torissi, D. (1996). Nurse-managed primary care. Nursing Management, 27, 44-47.

Lundeen, S. P. (1999). An alternative paradigm for promoting health in communities: The Lundeen community nursing center model. Family Community Health, 21(4), 15-28.

MacNee, C. L., Hemphill, J. C., \& Letran, J. (1996). Screening clinics for the homeless: Evaluating outcomes. Journal of Community Health Nursing, 13, 167-177.

Oros, M., Johantgen, M., Antol, S., Heller, B. R., \& Ravella, P. (2001). Community based nursing centers: Challenges and opportunities in implementation and sustainability. Policy, Politics, $\theta$ Nursing Practice, 2(4), 277-287.

Pohl, J. M., Vonderheid, S., Barkauskas, V., \& Nagelkerk, J. (2004). The safety net: Academic nurse managed centers' role. Policy, Politics e Nursing Practice, 5(2), 84-94.

Scott, C. B., \& Moneyham, L. (1995a). Perceptions of senior residents about a community-based nursing center. Journal of Nursing Scholarship, 27, 181-186.

Scott, C. B., \& Moneyham, L. (1995b). Advancing nursing centers within the health care revolution: The role of research. In B. Murphy (Ed.), Nursing centers: The time is now 
(pub No. 41-2629) (pp 215-231). New York: National League for Nursing Press.

Tanner, C., Pohl, J. M., Ward, S., \& Dontje, K. (2003). Education of nurse practitioners in academic nurse managed centers: Student perspectives. Journal of Professional Nursing, 19(6), 354-363.

Taylor, C. A., Resick, L., D’Antonio, J. A., \& Carroll, T. L. (1997). The advanced practice nursing role in implementing and evaluating two nurse managed wellness clinics: Lessons learned about structure, process and outcomes. Advanced Practice Nursing Quarterly, 3, 36-45.
Tyree, E. A., Henly, S. J., Schauer, J. B., \& Lindsey, D. L. (1998). Understanding preparation for primary health care roles in an academic nursing center. Journal of Nursing Education, 37, $337-344$

\section{Conflict of interest disclosure}

No relationship exists between any of the authors and the work represented in the text that might indicate a conflict of interest.

\section{Blackwell} Publishing

\section{Access your journals online}

\section{visit www.blackwell-synergy.com to:}

- Access article abstracts and sample issues for over 800 journals

Read full-text articles through your library subscription

Follow the research with reference links and citing article links

Register to receive journal tables of contents alerts

- Set up research alerts by keywords, topics, author names or other search terms

Get alerts when an article is cited

And much more.

\section{www.blackwell-synergy.com}

